16 a 18 de outubro de 2019 - Campinas | Brasil

\title{
Identificação e Estimação de Sistemas Dinâmicos: Aplicação em Robótica Móvel
}

\section{Eduardo H. Kobaicy*, André R. Fioravanti}

\section{Resumo}

Neste projeto, foram estudadas a identificação de sistemas dinâmicos e a estimação de estados através de ferramentas computacionais, a fim de implementar em uma plantaforma robótica terrestre experimental. A aplicação das ferramentas MATLAB System Identification Toolbox (SIT) e CVX geraram resultados distintos do modelo matemático linearizado. Testes foram executados para verificar qual dos métodos se aproxima melhor da plataforma experimental.

Palavras-chave: Identificação, estimação, controle.

\section{Introdução}

O principal objetivo do trabalho foi o estudo de métodos de estimação de estado dinâmicos de um veículo quando este não pode ser totalmente observado. Um problema correlato que também foi abordado é denominado por identificação de sistemas e trata de estimar parâmetros em sistemas dinâmicos. Foram realizados testes com dados coletados da plataforma experimental.

\section{Resultados e Discussão}

Inicialmente, para identificação do sistema com a SIT, foi utilizado o sistema descrito pelas equações em espaço de estado abaixo, que dependem da massa do veículo $(\mathrm{m})$, das distâncias dos eixos em relação ao centro de gravidade (a e b), do momento de inércia $\left(\mathrm{J}_{z z}\right)$, da velocidade longitudinal de referência (uret) e do coeficiente de amortecimento da suspensão $\left(\mathrm{C}_{\alpha}\right)$. Suas variáveis dinâmicas de estado são a velocidade lateral (v) e a velocidade angular ( $r$ ) e sua entrada de controle é o comando de direção $\left(\delta_{\mathrm{cmd}}\right)$. As equações que descrevem o comportamento dinâmico do veículo, simplificado para um modelo tipo bicicleta e a representação gráfica do sistema são apresentadas na Fig. 1.

$\left[\begin{array}{c}\dot{v} \\ \dot{r}\end{array}\right]=\left[\begin{array}{cc}\frac{-4 C_{\alpha}}{m u_{r e f}} & \left(\frac{2 C_{\alpha}(b-a)}{m u_{r e f}}-u_{r e f}\right) \\ \frac{2 C_{\alpha}(b-a)}{J_{z z} u_{r e f}} & \frac{-2 C_{\alpha}\left(a^{2}+b^{2}\right)}{J_{z z} u_{r e f}}\end{array}\right]\left[\begin{array}{l}v \\ r\end{array}\right]+\left[\begin{array}{c}\frac{2 C_{\alpha}}{m} \\ \frac{2 C_{\alpha} a}{J_{z z}}\end{array}\right] \delta_{c m d}$

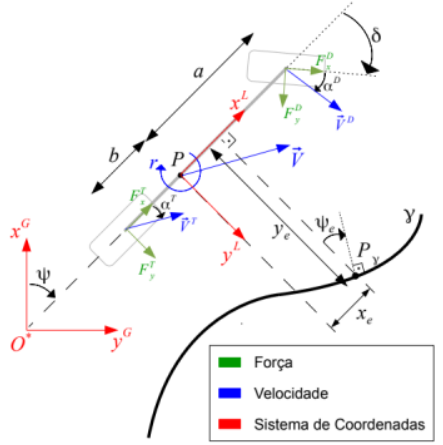

Figura 1. Modelo tipo bicicleta [1].

As entradas do comando de direção utilizadas na identificação foram do tipo up-chirp (por conta de seu conteúdo espectral e por serem aplicáveis na prática, diferentemente do impulso) e trem de pulsos com amplitudes variadas, porém limitadas. Ao identificar o sistema a partir da resposta do modelo não-linear de alta fidelidade, realizou-se a simulação da resposta do sistema identificado a uma determinada entrada, a fim de comparação com os dados provenientes do modelo linearizado e do modelo não-linear. Esta comparação é apresentada na Fig. 2.

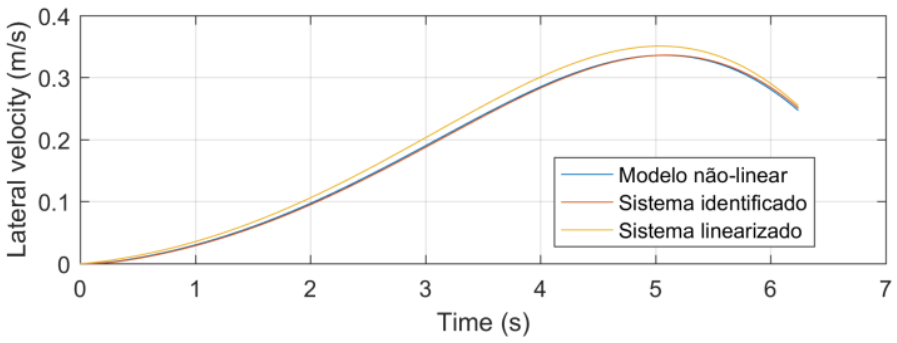

Figura 2. Comparação entre resposta dos sistemas.

Posteriormente foram realizados testes com a plataforma Auto-VERDE, utilizando a entrada up-chirp no comando de direção do veículo e diferentes velocidades longitudinais.

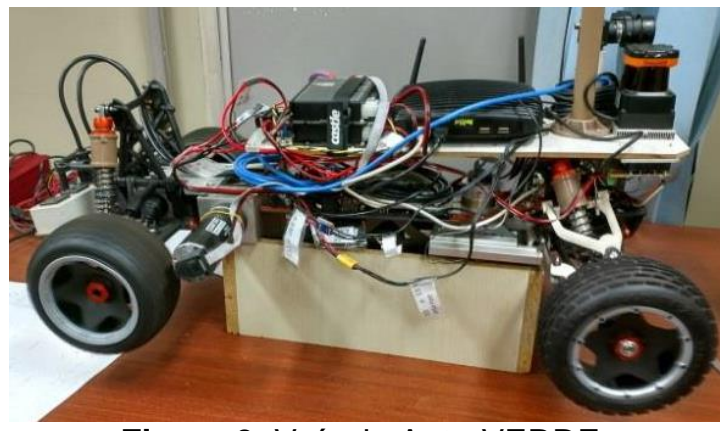

Figura 3. Veículo Auto-VERDE.

\section{Conclusões}

A execução deste trabalho mostrou que a presença de diferentes tipos de não-linearidades não previstas no modelo do sistema e a presença de ruído nos sinais analisados na identificação modificam significativamente a qualidade da estimação. Além disso, o modelo linearizado pode não apresentar a melhor resposta para algumas entradas pré-determinadas.

\section{Agradecimentos}

Agradeço ao professor André Fioravanti pela orientação e à equipe do ACCESLab pelo apoio no decorrer do trabalho.

1 CORDEIRO, R. A.; Modelagem e controle de trajetória de um veículo robótico terrestre de exterior. 2013, Dissertação de mestrado - Universidade Estadual de Campinas. 